\title{
Gaya manajemen konflik compromising dan dominating dalam mengurangi stres kerja perawat pelaksana
}

\author{
Adventy Riang Bevy Gulo1*, Erwin Silitonga ${ }^{2}$ \\ 1,2 Program Studi Ners, Fakultas Farmasi dan IImu Kesehatan, Universitas Sari Mutiara Indonesia \\ *Email: adventy_gulo@yahoo.com
}

\begin{abstract}
Conflict management styles among nurse managers in general hospitals, Medan-Indonesia
\end{abstract}

Background: Hospitals are required to improve the quality of health services so they can survive and thrive in the current era of national health insurance. Nurses are the most human resources in hospitals so they are required to have optimal performance. One of the factors that affect performance is conflict that causes work stress. Conflict management is expected to reduce the nurses'working stress.

Purpose: To identify the influence of compromising and dominating conflict management styles to reduce the nurses'working stress.

Method: A quantitative research with a correlative approach and cross sectional research design. The population was nurses at the Imelda Pekerja Indonesia Hospital and Martha Friska Hospital. Sampling using probability random sampling method with simple random sampling technique where the number of respondents was 105 nurses. The instrument used was a questionnaire containing 28 statements for conflict management style and 57 statements to measure the level of nurses' working stress. Analyze data with bivariate analysis to see the influence of compromising and dominating conflict management styles to reduce the nurses' working stress where the statistical test used is simple logistic regression (SLR) which is analyzed using a computer program.

Results: Finding that there was an influence of compromising conflict management style to reduce the nurses'working stress $(p=<0.001 ; P R=1.3395 \% \mathrm{Cl} 1.180-1.516)$, and there was an influence of conflict management style dominating to reduce the nurses'working stress $(p=0.012 ; P R=1.1095 \% \mathrm{Cl} 1.021-1.189)$

Conculsion: Compromising and dominating conflict management styles can reduce the nurses'working stress.

\section{Keywords: Conflict Management; Compromising; Dominating; Nurse Managers}

Pendahuluan: Rumah sakit dituntut meningkatkan kualitas pelayanan kesehatan sehingga mampu bertahan dan berkembang di era jaminan kesehatan nasional saat ini. Perawat adalah sumber daya manusia yang paling banyak di RS sehigga dituntut untuk memiliki kinerja yang optimal. Salah satu faktor yang mempengaruhi kinerja adalah konflik yang menyebabkan stres kerja. Memanajemen konflik diharapkan mampu mengurangi stres kerja perawat pelaksana. Tujuan: Untuk mengidentifikasi pengaruh gaya manajemen konflik compromising dan dominating dalam mengurangi stres kerja perawat pelaksana.

Metode: Penelitian kuantitatif dengan pendekatan korelatif dan desain penelitian cross sectional. Populasinya perawat pelaksana di RS Imelda Pekerja Indonesia dan RS Martha Friska. Pengambilan sampel menggunakan metode probability random sampling dengan teknik simple random sampling dimana jumlah responden sebanyak 105 orang perawat pelaksana. Instrumen yang digunakan berupa kuesioner yang berisi 28 pernyataan untuk gaya manajemen konflik dan 57 pernyataan untuk mengukur tingkat stres kerja perawat pelaksana. Analisa data dengan analisis bivariat untuk melihat adanya pengaruh gaya manajemen konflik compromising dan dominating dalam mengurangi stres kerja perawat pelaksana dimana uji statistik yang digunakan adalah simple logistic regression (SLR) yang dianalisis dengan menggunakan program komputer.

Hasil: Didapatkan bahwa terdapat pengaruh gaya manajemen konflik compromissing terhadap stres kerja perawat pelaksana $(p=<0,001 ; P R=1,3395 \% \mathrm{Cl} 1,180-1,516)$, dan terdapat pengaruh gaya manajemen konflik dominating terhadap stress kerja perawat pelaksana $(p=0,012 ; P R=1,1095 \% \mathrm{Cl} 1,021-1,189)$

Simpulan: Gaya manajemen konflik compromising dan dominating kepala ruangan berpengaruh dalam mengurangi stres kerja perawat pelaksana.

Kata Kunci: Gaya manajemen konflik; Compromising; Dominating; Stres Kerja Perawat 
Gaya manajemen konflik compromising dan dominating dalam mengurangi stres kerja perawat pelaksana

\section{PENDAHULUAN}

Salah satu organisasi yang menyelenggarakan pelayanan kesehatan perorangan secara paripurna yang menyediakan pelayanan rawat inap, rawat jalan dan gawat darurat adalah rumah sakit. Rumah sakit dituntut meningkatkan kualitas pelayanan kesehatan sehingga mampu bertahan dan berkembang di era jaminan kesehatan nasional saat ini. Kualitas pelayanan rumah sakit sangaT didukung oleh sumber daya manusia di dalamnya, salah satunya adalah perawat. Perawat adalah sumber daya manusia yang paling banyak di RS sehigga dituntut untuk memiliki kinerja yang optimal. (Kementerian Kesehatan Republik Indonesia, 2014).

Adanya konflik merupakan salah satu faktor yang turut mempengaruhi kinerja perawat dalam melaksanakan pelayanan keperawatan di rumah sakit (Robbins, \& Judge, 2015).

Hasil penelitian sebelumnya didapatkan bahwa beban kerja $(83,4 \%)$, rendahnya pengakuan atasan $(68,1 \%)$, kurangnya deskripsi yang jelas mengenai pekerjaan $(63,2 \%)$, dan ketidakadilan alokasi sumber daya $(59,5 \%)$ merupakan sumbersumber terjadinya konflik yang mengakibatkan stres kerja perawat (Moisoglou, Panagiotis, Galanis, Siskou, Maniadakis, \& Kaitelidou, 2014).

Menurut National Health System (NHS), bertambahnya tuntutan pada pelayanan keperawatan akan menyebabkan bertambahnya stresor kerja pada perawat. Stres yang terjadi pada perawat sangat mempengaruhi keadaan diri dari seorang perawat dan akan berkontribusi terhadap pelayanan ke pasien, dan pelayanan kesehatan secara keseluruhan (Farquharson, Bell, Johnston, Jones, Schofield, Allan, \& Johnston, 2013).

Stresor yang memengaruhi terjadinya stres kerja seorang perawat antara lain adanya konflik seperti konflik dengan pasien, dengan keluarganya, dengan dokter, perawat menghadapi pasien yang meninggal atau sekarat, beban kerja yang berlebih, dan ketidakpastian dalam pelaksanaan (Al Rasasi, Al Faisal, El Sawaf, Hussain, \& Wasfy, 2015).

Kesimpulan dari penelitian sebelumnya bahwa stresor yang menyebabkan stres kerja pada perawat karena adanya kurangnya kepuasan kerja, kurangnya motivasi, kurangnya komitmen kerja, dan kurangnya penghargaan (Sasumba, 2017). Eksploitasi pada perawat, rendahnya gaji dan kenaikan gaji yang lambat serta kurangnya istirahat pada perawat penyebab terjadinya stres kerja pada perawat (Rawal \& Pardeshi, 2014).

Stres kerja adalah hal yang penting untuk diperhatikan karena stres yang berkepanjangan dan tidak ditangani segera, akan menurunkan kinerja organisasi secara keseluruhan. Konflik yang terjadi di antara tenaga kesehatan di rumah sakit dapat mengakibatkan kinerja perawat dan pencapaian tujuan dalam melaksanakan asuhan keperawatan. Karena itu, peran kepala ruangan sangatlah penting untuk memanajemen konflik yang konstruktif dalam menciptakan lingkungan kerja yang produktif (Toren, \& Wagner, 2010).

Manajemen konflik dan stres kerja merupakan proses pihak yang terlibat konflik atau pihak ketiga yang menyusun strategi konflik dan menerapkannya untuk resolusi yang diinginkan (Baharudin, Kurdi, \& Lionardo, 2015; Rahim (2002) mengembangkan gaya manajemen konflik berdasarkan dua dimensi yaitu memperhatikan oranglain (concern for other) pada sumbu horizontal dan memperhatikan diri sendiri (concern for self). Beberapa gaya manajemen konflik diantaranya adalah compromissing dan dominating. Dari uraian tersebutlah maka penelitian ini bertujuan untuk melihat pengaruh gaya manajemen konflik compromissing dan dominating dalam mengurangi stres kerja perawat pelaksana di rumah sakit swasta Kota Medan.

\section{METODE PENELITIAN}

Jenis penelitian kuantitatif dengan pendekatan korelatif dan desain cross sectional untuk menganalisis gaya manajemen konflik kepala ruangan dalam mengurangi stres kerja perawat pelaksana di ruang rawat inap RS Swasta Kota Medan seperti di Rumah Sakit Imelda Pekerja Indonesia dan Rumah Sakit Martha Friska. Pengambilan sampel menggunakan metode probability random sampling dengan teknik simple random sampling dimana jumlah responden sebanyak 105 orang perawat pelaksana.

Instrumen yang digunakan berupa kuesioner yang berisi 28 pernyataan untuk gaya manajemen konflik dan 57 pernyataan untuk mengukur tingkat stres kerja perawat pelaksana. Proses anaisa data diawali dengan analisis univariat yaitu menjelaskan karakteristik responden yang meliputi jenis kelamin, usia, tingkat pendidikan, dan masa kerja. Dilanjutkan dengan analisis bivariat untuk melihat adanya pengaruh gaya manajemen konflik compromissing dan dominating dalam mengurangi

Adventy Riang Bevy Gulo ${ }^{1 *}$, Erwin Silitonga ${ }^{2}$ Program Studi Ners, Fakultas Farmasi dan llmu Kesehatan, Universitas Sari Mutiara Indonesia. *Email: adventy_gulo@yahoo.com 
Gaya manajemen konflik compromising dan dominating dalam mengurangi stres kerja perawat pelaksana

stres kerja perawat pelaksana dimana uji statistik yang digunakan adalah simple logistic regression $(S L R)$. Pertimbangan etik penelitian meliputi ethical clearence, izin dan rekomendasi dari Universitas Sari Mutiara Indonesia dan kedua RS, informed consent dari responden. Lulus uji etik di Komite Etik Penelitian Kesehatan Fakultas Kedokteran Universitas Muhammadiyah Sumatera Utara dengan nomor surat: 253/KEPK/FKUMSU/2019.

\section{HASIL}

Tabel 1. Karakteristik Responden N=105

\begin{tabular}{lcc}
\hline Karakteristik & Frekuensi (f) & Persentase (\%) \\
\hline Jenis Kelamin & 26 & \\
Laki-laki & 79 & 22,7 \\
Perempuan & & 75,2 \\
& & \\
Usia & 52 & 49,5 \\
$21-25$ tahun & 32 & 30,5 \\
26-30 tahun & 13 & 12,4 \\
$31-35$ tahun & 8 & 7,6 \\
$\geq 35$ tahun & & \\
Tingkat Pendidikan & - & - \\
SPK & 86 & 81,9 \\
DIII Keperawatan & 19 & 18,1 \\
S1 Keperawatan & & \\
& & \\
Lama Kerja & 17 & 16,2 \\
$0-6$ bulan & 23 & 21,9 \\
bln - 1 tahun & 3 & 2,9 \\
$1,1-1,5$ tahun & 16 & 15,2 \\
1,6 - 2 tahun & 46 & 43,8 \\
$\geq 2$ tahun & & \\
\hline
\end{tabular}

Hasil penelitian menunjukkan bahwa distribusi perawat pelaksana yang menjadi subjek penelitian, mayoritas berjenis kelamin perempuan $75,2 \%$, mayoritas berusia $21-52$ tahun $49,5 \%$, mayoritas responden berpendidikan D3 Keperawatan $81,9 \%$, dan mayoritas responden memiliki masa kerja $\geq 2$ tahun $43,8 \%$.

Tabel 2. Rerata Hasil Penilaian Perawat Pelaksana Terhadap Gaya Manajemen Konflik Kepala Ruangan N=105

\begin{tabular}{lccccc}
\hline Variabel & N & Min & Max & Mean & SD \\
& & & & & \\
\hline Compromissing & 105 & 7 & 20 & 13.12 & 3.855 \\
Dominating & 105 & 8 & 30 & 16.19 & 5.453 \\
\hline
\end{tabular}

Hasil penelitian menunjukkan bahwa rerata gaya manajemen compromissing sebesar 13,12 dengan nilai standar deviasi sebesar 3,85 dan rerata gaya manajemen konflik dominating sebesar 16,19 dengan nilai standar deviasi sebesar 5,45. 
Gaya manajemen konflik compromising dan dominating dalam mengurangi stres kerja perawat pelaksana

Tabel 3. Distribusi Frekuensi Stres Kerja Perawat Pelaksana N=105

\begin{tabular}{lcc}
\hline $\begin{array}{l}\text { Stress Kerja Perawat } \\
\text { Pelaksana }\end{array}$ & Frekuensi (f) & Persentase (\%) \\
\hline Tinggi & 0 & 0 \\
Sedang & 65 & 61.9 \\
Rendah & 40 & 38.1 \\
Total & 105 & 100 \\
\hline
\end{tabular}

Hasil penelitian menunjukkan bahwa stress kerja perawat pelaksana mayoritas sedang sebanyak 65 orang $(61,9 \%)$.

\section{Tabel 4. Analisis Gaya Manajemen Konflik Compromissing dan Dominating Dalam Mengurangi Stres Kerja Perawat Pelaksana}

\begin{tabular}{lcccc}
\hline \multirow{2}{*}{ Variabel } & \multirow{2}{*}{ Nilai $\mathbf{p}$} & \multirow{2}{*}{ PR } & \multicolumn{2}{c}{ 95\% C.I } \\
\cline { 4 - 5 } \cline { 4 - 5 } & & Lower & Upper \\
\hline Compromissing & $<0.001$ & 1.337 & 1.180 & 1.516 \\
Dominating & 0.012 & 1.102 & 1.021 & 1.189 \\
\hline
\end{tabular}

Hasil uji bivariat didapatkan bahwa terdapat pengaruh gaya manajemen konflik compromissing terhadap stress kerja perawat pelaksana $(p=$ $<0,001 ; \mathrm{PR}=1,3395 \% \mathrm{Cl} 1,180-1,516)$ artinya bahwa gaya manajemen konflik compromissing dapat menurunkan stress kerja perawat pelaksana sebesar 1,33 kali lebih besar dibanding dengan gaya manajemen konflik lainnya dan terdapat pengaruh gaya manajemen konflik dominating terhadap stress kerja perawat pelaksana $(p=$ $0,012 ; \mathrm{PR}=1,1095 \% \mathrm{Cl} 1,021-1,189)$ artinya bahwa gaya manajemen konflik dominating dapat menurunkan stress kerja perawat pelaksana sebesar 1,10 kali lebih besar dibanding dengan gaya manajemen konflik lainnya.

\section{PEMBAHASAN}

\section{Gaya Manajemen Konflik Compromising} terhadap stres kerja Perawat Pelaksana

Hasil uji bivariat pada penelitian ini menunjukkan bahwa terdapat pengaruh gaya manajemen konflik compromissing terhadap stress kerja perawat pelaksana $(p=<0,001 ; P R=1,33$ $95 \% \mathrm{Cl} 1,180-1,516)$ artinya bahwa gaya manajemen konflik compromissing dapat menurunkan stress kerja perawat pelaksana sebesar 1,33 kali lebih besar dibanding dengan gaya manajemen konflik lainnya.

Gaya compromising disebut juga give and take, dimana semua pihak menginginkan keputusan yang secara bersama-sama saling menguntungkan (Rahim, 2002).

Gaya ini sangat berguna ketika tujuan pihak yang sedang konflik saling eksklusif atau kedua pihak (seperti manajer dan karyawan) sama kuatnya dan menemukan jalan buntu dalam proses negosiasi. Hasil penelitian lain yang menghasilkan compromising pada posisi kedua didapatkan di berbagai negara seperti di Rumah Sakit di Amerika Serikat, Thailand dan di Oman (Cavanagh, 1991; Kunaviktikul, Nuntasupawat, Srisuphan, \& Booth, 2000; Al-Hamdan, Shukri, \& Anthony, 2011).

Gaya compromising merupakan gaya manajemen konflik yang hanya memberikan solusi sementara dan terkadang dapat menimbulkan konflik baru. Gaya compromising mengutamakan kepentingan kedua pihak, tetapi hanya memberikan solusi sementara dalam penyelesaian konflik. Compromising ditandai dengan adanya keadilan, solusi jangka pendek yang diputuskan secara cepat, dan memaksimalkan keuntungan serta meminimalkan kerugian. Gaya manajemen konflik compromising berpengaruh positif dan signifikan terhadap kinerja karyawan. Gaya manajemen konflik compromising memerlukan pengorbanan dari salah satu pihak yang terlibat konflik sehingga tidak dapat menaikan menurunkan tingkat stres dan meningkatkan kinerja karyawan. (Prause, \& Mujtaba, 2015; Huan, \& Yazdanifard, 2012). 
Gaya manajemen konflik compromising dan dominating dalam mengurangi stres kerja perawat pelaksana

Konflik tidak dapat dihindari, maka pendekatan yang baik untuk diterapkan para manajer adalah mencoba memanfaatkan konflik sedemikian rupa sehingga konflik dapat memberikan hal yang efektif untuk mencapai tujuan organisasi. Compromising merupakan gaya yang berada di tengah dengan mencari kesepakatan sementara tanpa memberikan keuntungan atau kerugian untuk kedua belah pihak. Hasil penelitian sebelumnya didapatkan bahwa individu yang terlibat dalam penerapan gaya compromising mudah untuk tidak puas dengan solusi sementara yang didapat dan menginginkan untuk keinginannya tercapai. Jika hal tersebut terjadi maka penerapan compromising tidak menghasilkan solusi sementara melainkan menghasilkan solusi yang lain (Huan, \& Yazdanifard, 2012).

Dalam keadaan tertentu, kompromi dapat berarti membagi perbedaan diantara dua posisi dan memberikan konsesi untuk mencari titik tengah. Indikator mengenai keterampilan yang diperlukan untuk menggunakan gaya manajemen konflik kompromi yang efektif meliputi; kemampuan bernegosiasi; mendengarkan dengan baik lawan konflik; mengevaluasi nilai; menemukan jalan tengah; dan memberikan konsesi (Baharudin, Kurdi, \& Lionardo, 2015).

Hasil penelitian menunjukkan terdapat pengaruh signifikan gaya manajemen konflik kolaborasi, menghindar, kompetisi, akomodasi dan kompromi terhadap kinerja karyawan secara simultan dengan stres kerja sebagai variabel intervening (Ramandhanta, 2017).

\section{Gaya Manajemen Konflik Dominating terhadap stres kerja Perawat Pelaksana}

Hasil penelitian ini menunjukkan bahwa terdapat pengaruh gaya manajemen konflik dominating terhadap stress kerja perawat pelaksana $(p=0,012 ; \mathrm{PR}=1,1095 \% \mathrm{Cl} 1,021$ $1,189)$ artinya bahwa gaya manajemen konflik dominating dapat menurunkan stress kerja perawat pelaksana sebesar 1,10 kali lebih besar dibanding dengan gaya manajemen konflik lainnya. Gaya manajemen konflik dominating disebut juga orientasi win-lose atau menggunkan kekuatan untuk mendapatkan suatu posisi. Orang yang dominating atau competiting ingin memenangkan tujuannya, dan akibatnya sering mengabaikan kebutuhan dan harapan pihak lain. Seorang supervisor bisa menggunakan gaya ini pada isu-isu yang dilaksanakan secara rutin ataupun pada kondisi-kondisi yang memerlukan pengambilan keputusan dengan cepat (Rahim, 2002).

Dalam suatu organisasi, individu yang mampu menangani konflik secara efektif dianggap sebagai komunikator yang efektif dan pemimpin yang mumpuni (capable). Mereka yang tidak dapat menangani konflik dengan secara efektif akan mengalami hambatan untuk mencapai tujuan organisasi, mempertahankan relasi yang positif dan keterpaduan atau kedekatan, dan problem solving (Gross \& Guerrero, 2000; Halimsetiono, 2014; Redmond, Jameson, \& Binder, 2016). Hasil penelitian sebelumnya menunjukkan bahwa gaya manajemen konflik dominating berpengaruh positif dan signifikan terhadap kinerja karyawan di Hotel Sheraton Surabaya (Fernando, Mihardjo, \& Widjaja, 2018).

Gaya dominating merupakan gaya manajemen konflik yang lebih sering mengutamakan diri sendiri daripada pihak lainnya. Dominating ditandai dengan adanya argumentasi untuk mengambil ahli kekuasaan di dalam suatu interaksi dan dominating sebagai competitive (DuBrin, \& Geerinck, 2015). Sedangkan pendapat yang lain menyebutkan bahwa dominating sebagai competing (Prause, \& Mujtaba, 2015). Hal ini didukung hasil penelitian sebelumnya bahwa gaya manajemen konflik dominating berpengaruh kinerja karyawan karena dapat meminimalisir stres kerja perawat (Rahim, 2002).

Gaya manajemen konflik dominating cenderung sering diterapkan oleh pemimpin kepada bawahan, namun bisa juga sebaliknya yaitu apabila konflik yang terjadi meluas dan melibatkan berbagai pihak. Sebagai contoh penerapan metode ini dilakukan di Afrika dimana perusahaan yang digunakan sebagai obyek penelitian menggunakan gaya dominating. Dalam kasus ini justru karyawan yang menerapkan gaya manajemen konflik dominan untuk mendesak atasannya dengan cara meminta kenaikan gaji. Pihak manajemen mengikuti permintaan karyawan, dan hal ini membuat karyawan menghargai pekerjaannya dan meminimalisir stresnya sehingga kinerja karyawan dapat ditingkatkan secara keseluruhan (Odoziobodo, 2015).

Dominating yang dipentingkan adalah kepentingan diri sendiri dan dalam hal ini yang dimaksud pada umumnya adalah atasan atau pihak yang lebih berkuasa atau individu yang memiliki karakter kepribadian bersifat otoriter atau dominan. Gaya ini dapat memberikan hasil yang

Adventy Riang Bevy Gulo"*, Erwin Silitonga ${ }^{2}$ Program Studi Ners, Fakultas Farmasi dan llmu Kesehatan, Universitas Sari Mutiara Indonesia. *Email: adventy_gulo@yahoo.com 
Gaya manajemen konflik compromising dan dominating dalam mengurangi stres kerja perawat pelaksana

baik ketika membutuhkan keputusan yang cepat. Kesimpulan penelitian sebelumnya menyebutkan bahwa lebih baik keputusan diambil oleh seorang individu saja yang memiliki kemampuan yang bagus dalam pengambilan keputusan daripada memilih keputusan lain yang tidak efektif (Huan, \& Yazdanifard, 2012).

\section{SIMPULAN}

Hasil penelitian menunjukkan bahwa distribusi perawat pelaksana yang menjadi subjek penelitian di Rumah Sakit Swasta Kota Medan, mayoritas berjenis kelamin perempuan $75,2 \%$, mayoritas berusia $21-52$ tahun $49,5 \%$, mayoritas responden berpendidikan D3 Keperawatan 81,9\%, dan mayoritas responden memiliki masa kerja $\geq 2$ tahun $43,8 \%$.

Hasil uji bivariat didapatkan bahwa terdapat pengaruh gaya manajemen konflik compromissing terhadap stress kerja perawat pelaksana $(p=$ $<0,001 ; \mathrm{PR}=1,3395 \% \mathrm{Cl} 1,180-1,516)$ artinya bahwa gaya manajemen konflik compromissing dapat menurunkan stress kerja perawat pelaksana sebesar 1,33 kali lebih besar dibanding dengan gaya manajemen konflik lainnya.

Lebih lanjut dijelaskan, terdapat pengaruh gaya manajemen konflik dominating terhadap stress kerja perawat pelaksana $(p=0,012 ; P R=1,10$ $95 \% \mathrm{Cl} 1,021-1,189)$ artinya bahwa gaya manajemen konflik dominating dapat menurunkan stress kerja perawat pelaksana sebesar 1,10 kali lebih besar dibanding dengan gaya manajemen konflik lainnya.

\section{SARAN}

Peneliti menyarankan kepala ruangan untuk menggunakan gaya manajemen konflik compromissing dan dominating dalam mengurangi stres kerja perawat dalam situasi tertentu, tetapi para kepala ruangan dapat juga menerapkan gaya manajemen lainnya disesuaikan dengan situasi dan kondisi yang terjadi di ruangan. Bagi perawat pelaksana diharapkan dapat meningkatkan komunikasi dengan atasan langsung dan turut berperan aktif dalam proses manajemen konflik yang dilaksanakan oleh kepala ruanagn. Bagi pihak RS, diharapkaan memberikan pelatihan yang berkelanjutan bagi para kepala ruangan maupun calon kepala ruangan perawat terkait manajemen konflik, dan mengoptimalkan pelaksanaan manajemen konflik secara terprogram dalam mengurangi stres kerja perawat pelaksana.

\section{DAFTAR PUSTAKA}

Al Rasasi, A., Al Faisal, W., El Sawaf, E., Hussain, H., \& Wasfy, A. (2015). Work-Related Stress Among Nurses Working in Dubai, a Burden for Healthcare Institutions. Am J Psychol Cogn Sci, 1(2), 61-5.

Al-Hamdan, Z., Shukri, R., \& Anthony, D. (2011). Conflict management styles used by nurse managers in the Sultanate of Oman. Journal of clinical nursing, 20(3-4), 571-580.

Baharudin, B., Kurdi, F. N., \& Lionardo, A. (2015). Analisis Perbedaan Tipe Kepribadian A dan B Terhadap Manajemen Konflik Interpersonal Pada Pegawai Rumah Sakit Khusus Mata Provinsi Sumatera Selatan. Psikis: Jurnal Psikologi Islami, 1(2), 25-33.

Cavanagh, S. J. (1991). The conflict management style of staff nurses and nurse managers. Journal of advanced nursing, 16(10), 1254-1260.

DuBrin, A. J., \& Geerinck, T. (2015). Human relations: Interpersonal, job-oriented skills. Pearson.

Farquharson, B., Bell, C., Johnston, D., Jones, M., Schofield, P., Allan, J., \& Johnston, M. (2013). Nursing stress and patient care: real-time investigation of the effect of nursing tasks and demands on psychological stress, physiological stress, and job performance: study protocol. Journal of advanced nursing, 69(10), 2327-2335.

Fernando, M., Mihardjo, A. I., \& Widjaja, D. C. (2018). Analisis pengaruh gaya manajemen konflik terhadap kinerja karyawan di hotel sheraton surabaya. Jurnal Hospitality dan Manajemen Jasa, 6(2).

Gross, M. A., \& Guerrero, L. K. (2000). Managing conflict appropriately and effectively: An application of the competence model to Rahim's organizational conflict styles. International journal of conflict management, 11(3), 200-226. 
Gaya manajemen konflik compromising dan dominating dalam mengurangi stres kerja perawat pelaksana

Halimsetiono, E. (2014). Peningkatan komitmen organisasi untuk menurunkan angka turnover karyawan. Kesmas: National Public Health Journal, 8(8), 339-345.

Huan, L. J., \& Yazdanifard, R. (2012). The difference of conflict management styles and conflict resolution in workplace. Business \& Entrepreneurship Journal, 1(1), 141-155.

Kementerian Kesehatan Republik Indonesia. (2014). Permenkes, R. I. Nomor 56 tahun 2014 tentang Klasifikasi dan Perizinan Rumah Sakit. Jakarta: Depkes Republik Indonesia.

Kunaviktikul, W., Nuntasupawat, R., Srisuphan, W., \& Booth, R. Z. (2000). Relationships among conflict, conflict management, job satisfaction, intent to stay, and turnover of professional nurses in Thailand. Nursing \& health sciences, 2(1), 9-16.

Moisoglou, I., Panagiotis, P., Galanis, P., Siskou, O., Maniadakis, N., \& Kaitelidou, D. (2014). Conflict management in a Greek public hospital: Collaboration or avoidance. International journal of caring sciences, 7(1), 75-82.

Odoziobodo, S. I. (2015). Integrity and conflict resolution in Nigeria: An analysis of trade disputes between the Federal Government of Nigeria and the academic staff union of universities, ASUU. European Scientific Journal, 11(22).

Prause, D., \& Mujtaba, B. G. (2015). Conflict management practices for diverse workplaces. Journal of Business Studies Quarterly, 6(3), 13.
Rahim, M.A. (2002). Toward a theory of managing organizational conflict. International journal of conflict management, 13(3), 206-235.

Ramadhanta, A. (2017). Pengaruh Gaya Manajemen Konflik Kolaborasi, Menghindar, Kompetisi, Akomodasi dan Kompromi terhadap Kinerja Karyawan dengan Stres Kerja Sebagai Variabel Intervening di RS PKU Muhammadiyah Yogyakarta (Doctoral dissertation, Universitas Islam Indonesia).

Rawal, C. N., \& Pardeshi, M. S. A. (2014). Job stress causes attrition among nurses in public and private hospitals. IOSR Journal of Nursing and Health Science, 3(2), 42-47.

Redmond, V., Jameson, J. K., \& Binder, A. R. (2016). How superior-subordinate relationship quality and conflict management styles influence an employee's use of upward dissent tactics. Negotiation and Conflict Management Research, 9(2), 158-176.

Robbins, S. P, \& Judge, T. A (2015). Perilaku Organisasi. Jakarta: Salemba Empat, edisi ke-6

Sasumba, A. (2017). Gambaran stres kerja perawat di ruang rawat bedah rsud wates (Doctoral dissertation, STIKES Jenderal Achmad Yani Yogyakarta).

Toren, O., \& Wagner, N. (2010). Applying an ethical decision-making tool to a nurse management dilemma. Nursing Ethics, 17(3), 393-402.

\footnotetext{
Adventy Riang Bevy Gulo ${ }^{1 *}$, Erwin Silitonga ${ }^{2}$ Program Studi Ners, Fakultas Farmasi dan llmu Kesehatan,
} Universitas Sari Mutiara Indonesia. *Email: adventy_gulo@yahoo.com 